Moore, S. \& Stein, W. H. (1951). J. biol. Chem. 192, 663.

Moore, S. \& Stein, W. H. (1954a). F. biol. Chem. $211,893$.

Moore, S. \& Stein, W. H. (1954b). F. biol. Chem. 21x, 907.

Spackman, D. H., Stein, W. H. \& Moore, S. (1958). Analyt. Chem. 3o, i т go.

Synge, R. I.. M, (1951). Biochem. 7. 49, 642 .

Thomson, A. R. (1967). In Proc. 5th Technicon Colloquium on Amino Acid Analysis p. I 16. Domont, France: Technicon International Division.

Van Slyke, D. D., Dillon, R. T., MacFadyen, D. A. \& Hamilton, P. (I941). F. biol. Chem. 141, 627.

\title{
The determination of tryptophan in biological materials
}

By R. A. Evans, M. T. Nadeem Chaudry and A. G. S'Tephens, Department of Biochemistry and Soil Science, University College of North Wales, Bangor

The determination of tryptophan in solution may be accomplished by a variety of methods. These are based upon (I) ultraviolet spectroscopy, (2) spectrofluorimetry, (3) colorimetry of the reaction with $p$-dimethyl amino benzaldehyde, and (4) chromatography followed by colorimetry of the reaction with ninhydrin.

When these methods are applied to tryptophan occurring in protein-bound form in biological materials, problems arise which have not yet been solved on a batch basis, still less by automation. In plant materials, in particular, the presence of interfering substances causes irrelevant spectroscopic absorption and prevents the application of methods (I) and (2).

Method (3) has been widely applied. In the method of Spies \& Chambers (1949), the protein is solubilized by treatment with $19 \mathrm{~N}$-sulphuric acid. In the method of Miller (1967), hydrolysis with barium hydroxide is employed, while the method of Lombard \& de Lange ( $\mathrm{g}^{6} 5$ ) uses papain to hydrolyse the protein enzymatically. All these methods depend upon the specificity of the colour reaction. In method (4) ion-exchange chromatography has been automated and provides specificity, but the requirement for hydrolysis of the protein remains and cannot yet be automated.

Hydrolysis with sodium hydroxide instead of barium hydroxide avoids mechanical and absorptive losses since the acidified hydrolysate can be applied directly to the column. The application of corrections for hydrolytic losses based upon recovery of added tryptophan is questionable, in view of the different behaviour of free and protein-bound tryptophan to hydrolysis in the presence of some reducing agents.

\section{REFERENCES}

Lombard, J. H. \& de Iange, D. J. (1965). Analyt. Biochem. 1o, 260.

Miller, E. L. (1967). F. Sci. Fd Agric. 18, 381.

Spies, J. R. \& Chambers, D. C. (I949). Analyt. Chem. 2I, 1249.

\section{Automated analysis of peptides}

By W. Bolton, J. M. McNab and J. C. Blair, ARC Poultry Research Centre, King's Buildings, West Mains Road, Edinburgh 9

The results to be given were obtained with a Technicon peptide analyser (Catravas, 1964). In our system the peptides are separated on a cation exchange resin and the 
resulting effluent is divided into two. In one stream, the peptides are mixed with the colour-developing reagent, while in the other the peptides are hydrolysed into their constituent amino acids before colour development. By the insertion of a timedelay coil in the unhydrolysed stream, the two effluents arrive at their respective colorimeters at the same time and are recorded simultaneously on a 2 -pen recorder. The chromogen generally reacts with peptides only at their terminal amino group, whereas each of the liberated amino acids reacts. Therefore a comparison of the peaks given by the unhydrolysed and hydrolysed streams yields a measure of the number and size of the peptides present in the sample. In spite of the difficulties encountered with this system it has possible applications in the analysis of biological materials.

\section{REFERENCE}

Catravas, G. N. (1964). Analyt. Chem, 36, 1146.

\section{Determination of total amino acid concentrations in plasma}

\section{By J. S. Slater and E. Joan Dunnett, Moredun Research Institute, Gilmerton, Edinburgh}

An automated method has been developed for the direct measurement of plasma total amino acid concentrations using a ninhydrin-hydrazine reagent (Research Bulletin no. 20, Technicon Instruments Ltd). The analytical system is shown on Fig. I.

Plasma $(0.1 \mathrm{ml})$ is diluted $\mathrm{I}: \mathrm{I} 0$ with $0.85 \% \mathrm{NaCl}$ containing $0.5 \% \mathrm{BRIJ}_{35}$ and dialysed against the same saline solution. Standards are introduced hourly and alternate cups filled with saline to improve wash out. The rate of analysis is sixteen samples/h. Replicate analysis on the same plasma at varying dilutions gave a total amino acid concentration of $3.04 \pm 0.15 \mathrm{mM}$ as norleucine (20). Interference by urea is negligible and ammonia contributes less than $2 \%$ of the total colour at the concentrations found in fasting plasma.

Diffusion of individual amino acids through the dialyser membrane varied between $33 \%$ and $4 \mathrm{I} \%$. Colour yields varied considerably but all identifiable plasma amino acids showed a linear relationship between concentration and absorbance up to optical densities of $\mathrm{r} \cdot \mathrm{O}$.

This method has been used extensively in studies of ovine maternal and foetal plasma. Results may be corrected to give an approximation of the true total amino acid concentration using the weighted mean norleucine equivalent (Prenton \& London, 1967). In comparison with values obtained by ion exchange chromatography, recoveries of total amino acids by the present method were: maternal plasma I06.I $\pm 4 \cdot 0 \%$ (I 2 ), foetal plasma I02. I $\pm 7 \cdot 2 \%$ ( 13 ).

In maternal and foetal samples taken simultaneously from anaesthetized ewes 